\title{
Overcoming Obstacles: Portrayal of Saudi Women through Art
}

\author{
Nouf Alajmi \\ College of Art and Design, Princess Noura University, Riyadh, KSA \\ Email: msenan@gmail.com
}

How to cite this paper: Alajmi, N. (2019) Overcoming Obstacles: Portrayal of Saudi Women through Art. Art and Design Review, 7, 55-67.

https://doi.org/10.4236/adr.2019.72006

Received: February 27, 2019

Accepted: May 7, 2019

Published: May 10, 2019

Copyright (C) 2019 by author(s) and Scientific Research Publishing Inc. This work is licensed under the Creative Commons Attribution International License (CC BY 4.0).

http://creativecommons.org/licenses/by/4.0/

\begin{abstract}
This research discusses two important and long-controversial topics in Saudi society: women and the arts. The focus is on the difficulties women in Saudi Arabia have experienced in different aspects of life and how they are depicted in the art of many Saudi female artists' expressions of their acknowledgment of the issues and their disagreement with the current status quo. This study presents a survey of the history of women in the Kingdom of Saudi Arabia, highlighting the obstacles they have overcome throughout the years to achieve a conservative form of liberty. The challenges these women have encountered throughout the years are revealed and how Saudi female artists have highlighted these challenges in their works of art to help raise awareness to these issues.
\end{abstract}

\section{Keywords}

Saudi Women, Saudi Arabia, Saudi Art, Saudi Society, Contemporary Art, Controversy

\section{Introduction}

It may be true to say that the subject, "what is a woman?" is one of the most difficult topics of discussion today. Throughout the years, research has been conducted on gender differences and lack of opportunities for females throughout the world. The Muslim world has been under attack (Al-Resayes, 1999) by Western society for not giving women their rights, with Saudi Arabia being one example. Saudi Arabia is ruled by Islamic Law, giving rise to apprehensions in Western countries regarding the professional competency of Saudi females, as well as the potential for their oppression. However, these concerns have not been borne out by scientific study. As a result of increasing enrolment of women in all levels of education and various fields of employment (Aldehailan, 
2007) and aspects of public life in Saudi Arabia, the last 10 years witnessed a growing participation of women in senior management positions and in the decision-making process in public and private sectors (Al-Ahmadi, 2011). Recent developments indicate a clear strategic direction of policy makers and development plans in Saudi Arabia towards an even greater role for women in public life and into top leadership positions in public domains (AlMunajjed, 2010). Nonetheless, despite the successes that Saudi women have achieved, it is clear they encounter difficult circumstances and it is important to shed some light on the constraints and controversies that Saudi women have endured (Aldehailan, 2007). Saudi women have proven themselves to be relentless and strong fighters who have not succumbed to the debilitating prospects of not being equally integrated to their male counterparts within the Saudi workforce (AlMunajjed, 2010).

During the 1980s and 1990s Saudi society was influenced by an unofficial religious discourse that evolved from being purely religious to becoming religious-political, especially following the Gulf War in 1991 (Al-Atawneh, 2009). This trend, especially in the absence of counter-discourses, contributed to shaping the current social and cultural structure of Saudi society with its underlying complexities and inconsistencies. Social factors were perhaps the most challenging for women because they maintained prevailing norms and perceptions, including the pretext of "exclusiveness" (khususiyyah), which is the perception many Saudis have of their society and culture. It is argued that since the country is the birthplace of Islam and the land of the religion's two most holy cities, Saudi Arabia must preserve a unique Islamic identity and the distinct social characteristics of Saudi society. Furthermore, the issue of women and their situation is a highly politicised one among the various factions in Saudi society (Aldehailan, 2007).

The fast economic development in the 1970s, brought attention to women's issues in Saudi Arabia in a way that could not be ignored (Al-Ahmadi, 2011), especially with dramatic social change that is still ongoing due to the Arab uprising. Issues regarding women's rights and responsibilities in the development process have been equally controversial among both conservatives and progressives (Obaid, 2011) in Saudi society. The historical socioeconomic and political conditions of Saudi Arabia are an essential aspect of understanding a woman's position in the Saudi society. Before exploring women's status in Saudi Arabia, it is important to review some of the political and social events that have contributed to shape the status of women in the Saudi society.

Many judges and legal scholars tend to maintain social norms through their legal actions, decisions and judgments (Aldehailan, 2007), and the resultant intermingling of these two constructs (norms and law) affects women in particular. For example, women's freedom of mobility (AlMunajjed, 2010) and the restrictions imposed by the guardianship system are both heavily rooted in cultural customs, but are also backed by the legal system (AlMunajjed, 2010). This situation is further complicated by the fact that until recently women were not al- 
lowed to study law (Baki, 2004). Research has indicated there seems to be a general consensus in Saudi Arabia among both women and men that the problematic nature of granting women's rights stems not from sharia itself, but from customary laws and practices, which are responsible for restricting women's freedom to control their own lives (AlMunajjed, 2010). This leads to situations such as women being unable to apply for their own passports because the governing regulations for the issuing and renewal of Saudi passports require women to be accompanied by a male guardian. A 2004 study (Hamdan, 2005) was presented as part of the National Dialogue (al-hiwar al-watani), an annual event organised by the King "Abd al-" Aziz Centre for Dialogue, established in 2003 to foster tolerance and understanding. This study examined Saudi women's increasing awareness of the differences between norms, customs, and religion. The study confirmed that customs and norms are mixed in with and inform religious provisions, influencing how Saudi women perceive their rights and position (Hamdan, 2005).

In addition, Saudi Arabia has an exceptional Islamic inheritance and an established traditional culture. Yet, the country has undertaken and is still pursuing modification (Baki, 2004), most of it initiated by the Saudi government through modern development plans. These plans and agendas (Baki, 2004) have formed the Saudi way of life in general and affected women specifically. Interestingly, Saudis appear to have a unique type of reaction to such change and modernization. Bencomo \& Wilcke (2008) suggest it should be recognized that modern development was actively introduced by the Saudi government when the country was united (1932), as part of the process of nation building to transform Saudi Arabia into a modern state and to improve social welfare.

Thus the nation's development, through the process of "modernisation" (Al-bakar, 1997), was self-consciously introduced by the government to change inherited socio-economic structures in order to progress towards a state of "modernity" (Al-bakar, 1997), without changing the "traditional" (Bencomo \& Wilcke, 2008) religious and cultural values and customs of the family and society. The term "traditional" refers to the long established and widely-held traits in society, family or individual that contrast with modern traits in a modern society. In addition, the process of development was accelerated when the income from oil production increased in the 1970s (Baki, 2004).

The issue of integrating women in development has been a major focus of research in the Arab countries. Abu-Shekhah (1990) argues that historical circumstances and traditional values have forced women to become an unused power for development, and this has introduced an element of backwardness in many areas of social life. But this view ignores the fact that women have always participated in production, whether paid or unpaid, as part of their household family roles. Another perspective sees the division of labour in traditional societies as based on the man doing the hard and muscular work and women being responsible for making clothes, preparing food, breeding animals and helping in agriculture. This conceptualization shows the complementarity of traditional 
roles, each resulting in similar levels of production (Al-Resayes, 2010). This picture (Al-Resayes, 2010) has changed only recently when a more modern economy was introduced and the family became increasingly dependent on the market for its needs. This shift caused women to lose some of their traditional productive roles, and it became important for them and their families to find other ways to increase the family income to pay for things the family needs in a modern cash economy. Thus, women have been obliged to enter the labour force to fulfil these needs in many Arab countries, raise the need for their education and training as well (Abu-Shekhah, 1990).

Many women academics have become successful in universities but, as Devos (2004) states, they have had to fight through many challenges and barriers to achieve this success. Education in Saudi Arabia is based on the segregation of females and males in separate institutions, but both men and women have the opportunity to hold jobs in higher education. Therefore, in the education sector, marginalisation and inequality (Al-Atawneh, 2009) in hiring women does not exist in Saudi Arabia, because women are needed to teach and work in the female schools, colleges and universities. Nevertheless, Saudi women academics have other problems within the conservative culture (Saddeka, 1994).

As previously stated, any new development or transition in Saudi society seems to be difficult for Saudis to accept at first. Saudi people initially believed that girls going to school would bring shame on the family (Devos, 2004), however over time the development of girls' education has gradually been accepted (Alassem, 1993).

Ben-Mahfodh (1997) considers that for a long time, the conservative Saudi culture put women at a disadvantage in terms of obtaining an education. Women were not granted the right to receive education in public schools until 36 years after men were (Elamin \& Omair, 2010). This was due to a misinterpretation of the Islamic religion, which actually encourages both men and women to seek education (Al-Resayes, 2010). Over time, Saudi society has worked within the Islamic religion and its conservative culture to find suitable ways of providing similar education for women and men (Obaid, 2011) that is in keeping with Shari'a Law on which the government is based (Lacroix, Haykel, \& Heghammer, 2015) by establishing the segregation of the education system based on gender to ensure privacy for women in their own institutions (Obaid, 2011).

According to Alassem (1993), the conservative nature of Saudi culture guided the government to prevent women from progressing, sometimes in order to satisfy the majority of Saudi society-ironically, including some women. As a result, even now some women still refuse to accept the changes (AlMunajjed, 2010). For example, a large number of Saudi women are opposed to women driving in Saudi Arabia (Aldehailan, 2007). This controversial issue (Al-Shetaiwi, 2002) has caused countless problems for both working and non-working women. As a result, the issue of driving is still being debated, while women's education has been established for forty years (Ben-Mahfodh, 1997). It is important to recognize that women driving cars does not conflict with the Islamic religion, 
but is rather an ideology of the Saudi society.

\section{The Saudi Art Scene}

Saudi Arabia has a historically rich relationship with the arts (Al-Resayes, 2010), from the intricate mosaics and calligraphy of its mosques to the vivid culture of the Bedouin tribes. However, while an appreciation for traditional art is important, it does not play the same role as contemporary art. Up until the last fifteen years, the kingdom did not have any public contemporary art galleries (Ayad \& Blackburn, 2014). Now, with around ten modern art galleries (Al-Senan, 2007) located in Jeddah, the country's most liberal city, Saudi Arabia is able to feature both male and female contemporary artists. One of the most recent additions to the Saudi art scene is Al-Hangar (Ayad \& Blackburn, 2014), a warehouse where young artists led by Ramy Alquthamy and Nasser Al Salem created an exhibition that was viewed not only by Saudi nationals, but also by representatives from the British Museum, the Pompidou, and the Arab Fund for Arts and Culture. While impressing foreign correspondents through the intellectual medium of contemporary art is a brilliant way to show the world a side of Saudi Arabia unrepresented by the media, the artists themselves are more invested in creating a "sense of community" out of the Saudi art scene and starting a "cultural movement" within Saudi Arabia (Ibrahim, 1998). These two concepts are especially important in a kingdom where young people are surrounded by a restrictive environment. The emergence of an art scene engaged the young Saudi populace to artfully spread awareness of their home country, while simultaneously instilling a strong sense of national pride (Al-Resayes, 2010).

However, the conservative culture and strict governmental laws found in Saudi Arabia do not provide much opportunity to exhibit controversial content (Athimin, 1995). Some instances of Saudi contemporary artists testing the waters in their own country have been documented, including many who push the boundaries of self-expression in their own country where direct criticism of the authorities is not tolerated (Athimin, 1995). Most of these artists have to find imaginative ways to manoeuvre around the censors to ensure the continuation of a local art scene that is still at an early stage of development (Al-Resayes, 2010). They are also trying to avoid being overly controversial (Ayad \& Blackburn, 2014) and stepping on too many toes because that in a way will be counter-productive. Thus, the purpose has become to convey the artist's message without having to offend anyone. While, many Saudi artists argue that their art is not understood by the majority of the Saudi public, it is evident they now enjoy a greater level of freedom of expression than they ever did before (Al-Resayes, 2010).

\section{Women and Art in Saudi Arabia}

The representation of Saudi women in Saudi Arabia or in the West has been and still remains a controversial issue, due to the extremely conservative nature of 
Saudi society. Although, a casual thought of Saudi women evokes stereotypical images in the mind, the reality is that Saudi women differ greatly, and that is not to be seen with a negative connotation. Still, the Saudi social structure, which is derived from Islamic interpretations and Arab culture and traditions, often underlines the laws and regulates behaviours in almost every aspect of Saudi women's lives.

Though considered one of the most restrictive countries in the world in terms of social policies, Saudi Arabia is indeed beginning to have a progressive arts scene (Al-Resayes, 1998). Art galleries were simply non-existent until the $21^{\text {st }}$ century in Saudi Arabia (Al-Resayes, 1998) but now there are tens (Al-Resayes, 1998) of mostly private art galleries in each major city and the numbers are growing. For example, Jeddah Art Week is one of the Saudi contemporary art initiatives established to encourage the growing art scene in Jeddah. It has become apparent these artists involved are not saying merely that art exists in Saudi Arabia, but they are insisting it is an acceptable part of Saudi culture.

Galleries and exhibitions today have the opportunity to act as a social change agent or influence within a community by exhibiting current topics, emotional issues, or counter-cultural subjects for the further education and inspiration of visitors (Ayad \& Blackburn, 2014). Indeed, "when a thing ceases to be a subject of controversy, it ceases to be a subject of interest" (Hazlitt, 1830). Recently, rare criticism has been observed through social media towards the government regarding Saudi Arabia's art policy (Atkinson, 2015). In 2015, an art campaign was launched by three Saudi female artists which had sparked conversations about the place of art in the conservative Gulf Kingdom with an abundant amount of disruptive posters (Atkinson, 2015). The artists displayed more than 400 posters bearing the catchphrase "Art is Halal" around the streets of the capital city of Riyadh (Atkinson, 2015). During the interview with the Middle East Eye, one of the female artists stated that, "the goal behind the campaign was to provoke a public debate about the limits of freedom of expression in art". These female artists hoped to stir up the people's emotions by engaging them in discussions and looking deeper into the meaning of art and the limits of "halal" and "haram"1 (Atkinson, 2015). The provocative message and intent of these posters, had the Saudi society deliberating, spawning hashtags and fierce online debate over the role of art in Saudi Arabia.

In a world seemingly dominated by business and politics, it can be easy to forget the importance of art in society (Al-Resayes, 1999). Young female Saudi artists who create universally-acclaimed and relatable works are showing the world a side of Saudi that outsiders have rarely seen before. To understand that people, in what seems like a very distant and different part of the world to most, have recognizable and resonant thoughts, interests and ambitions, is inspirational, especially in juxtaposition to the biased scenes of oppression shown by Western media (Riedy, 2013). The future of contemporary art in Saudi Arabia looks aus${ }^{1}$ Haram is an Arabic term that defines anything that is prohibited according to the Islamic law. Halal means permitted or lawful in Islam. 
picious (Atkinson, 2015) with the motivating exhibitions at Al-Hangar, as one example. This will not only open the eyes of Saudi nationals (Al-Resayes, 2010), but the eyes of the world around them as well.

\section{Saudi Female Artists}

Manal Al Dowayan, is a female artist born and raised in the Eastern Province of Saudi Arabia. Her artistic practice concentrates on several themes including active forgetting, archives, and collective memory, with an emphasis on the state of Saudi women and their portrayal. She acknowledged social groups such as the oil men and women of Saudi Arabia in her project, If I Forget You Don't Forget $\mathrm{Me}$, and has addressed the effect of mass media on propagating deliberate obliteration of identities in her project Crash, which highlights the unnamed Saudi teachers dying in car crashes across Saudi Arabia. Her participatory projects, including-Tree of Guardians, Esmi-My Name, and Suspended Together, have attracted hundreds of women to the use of art as a new platform to address social injustice.

In 2011, Al Dowayan exhibited one of these art pieces titled, Esmi-My Name to address a controversial topic involving women's names. The inspiration for this particular work stems from the close relationship between a woman's name and her identity, and targets the Saudi taboo against the public use of women's names. Many Saudis, both men and women, consider it improper and impertinent to use a woman's name in public. My Name is an installation project that consists of seven massive strings of Muslim prayer beads hanging down from the ceiling, their long tassels suspended just above the floor. Each string consists of approximately 30 soccer-ball sized beads on which a Saudi woman has written her name in bold, black Arabic script. The most important aspect of al Dowayan's artwork is the fact that each bead displayed a woman's name. Al Dowayan has observed disdainful attitudes towards female names in Saudi Arabia, something she felt had no origin in the Quran or Islamic teachings. In her art, these prayer beads become a way to liberate female names and, in a sense, purify them. With My Name, Al Dowayan suggests that some traditions, which are often justified as demonstrating respect for women, can at the same time serve to deprive them of their individuality and their identity. Through this art exhibition, Al Dowayan hoped to empower not only the Saudi women who participated in its production, but also the Saudi women who viewed it. By bringing awareness to this controversial topic, she sent a loud and clear message that Saudi women will not allow their names to be erased, replaced, or become a source of shame.

Another example of a Saudi female artist who creates art as a product of social issues which spark controversy is, Ms. Saffaa. Ms. Saffaa represents herself as both a cultural activist and a visual artist. She was challenged by Saudi authorities for not having a male guardian with her whilst studying for her bachelor's degree in Australia (in 2009) through a scholarship funded by the Saudi government. During that year, the Human Rights Watch released a report critical of 
Saudi laws prohibiting women from travelling, or marrying without the permission of a male guardian. The 79-page report ${ }^{2}$, examined in detail the array of formal and informal barriers women in Saudi Arabia face when attempting to make decisions or take action without the presence or consent of a male relative.

A Saudi female-led protest gained steam after this report which gave birth to the hashtag, \#iammyownguardian, and a petition was signed by thousands, protesting these Saudi guardianship laws. Ms. Saffaa says the inspiration for her art came from continuous run-ins with Saudi authorities over this particular issue. Her posters, featuring a face shrouded in the Saudi shemagh ${ }^{3}$ and the hashtag \#iammyownguardian, became emblematic of the movement. They were plastered on Saudi streets, retweeted and sold online. For Ms. Saffaa, speaking up has had its expense. The artist, who uses only her first name, has suffered harassment and been reported to Saudi authorities by trolls. At an exhibition at Melbourne's Islamic Museum of Australia, Ms. Saffaa was antagonised by a man demanding to know why she was exposing Saudi's dirty laundry to the west. Saffaa says her work is motivated not only by political injustice but an instinctual need for self-expression.

In the past 10 years, legal restrictions on Saudi women have relented slightly. Saudi women have gained some access to political positions as well as, increased autonomy in the labour market, and there have been efforts by the government to better address domestic violence. And social media has been particularly critical to the growth of the hashtag movement because forms of public protest, such as marching in the street, are illegal in Saudi Arabia.

Still, provoking dialogue on subjects that challenge convention remains central to the work of many Saudi artists, including, Manal al-Dowayan's whose installation "Suspended Together", showed doves made of porcelain frozen in mid-flight, each carrying a travel permit-a reference to the rule that requires women to obtain a male relative's permission to travel abroad. For that project, al Dowayan collected travel permits from many accomplished Saudi women-professors, scientists and writers among them. While challenging conceptions of the role of women in Saudi society is still contentious, al Dowayan's art allows her to protest one controversial element, while supporting her work with religious doctrine.

Similarly, Sarah Abdullah, a Saudi female artist who also works with film and has exhibited at the $55^{\text {th }}$ Venice Biennale and Copenhagen's Louisiana Museum of Art, reconstructs the ban on female driving as a performative project in her 2012 video Saudi Automobile. Abdallah treats a ruined vehicle meant for transport and utility as a decorative object, painting it a shade of pale pink throughout the extent of her ten-minute performance. In doing so, she conveys to the viewer a sense of impotence, regarding both the vehicle's motionlessness, and the impossibility of her own desire for movement and mobility.

\footnotetext{
2“Boxed In: Women and Saudi Arabia's Male Guardianship System". Human Rights Watch report (http://www.hrw.org).

${ }^{3} \mathrm{~A}$ Shemagh is a traditional Middle Eastern headdress or scarf worn by men.
} 
Similar thematic issues of gender equality within Saudi society are addressed in Ahaad Almoudi's My Saudi Couple, a pair of his-and-her detergent bottles printed with male (white) and female (black) stickers. The commentary on this piece is tongue-in-cheek rather than explosive; it is less of an attempt to make the Saudi world more digestible to a Western audience than it is an elusive reminder of how experiences of inequity are extended to experiences of global commercialism and thus shared rather than being tied to a particular culture's norms.

Another addition to the Saudi female artist list, is Fawziah Al-Thobaiti, a Saudi female who combines contemporary typography, illustration and photography with Arabic calligraphy as a means of creating works-both digitally and by hand-that depict the real life of today's Saudi women. Her art forms a cultural representation offering viewers an appreciation of the ongoing successes and challenges of Saudi women at present, highlighting issues such as: women's rights, marriage, driving laws, education, and achievements abroad. In one of Althobaiti's exhibitions, she set out to accentuate the changes that have helped Saudi women gain their rightful positions in society. In this piece, she presents three paintings of women draped in the black abaya with a white box framing different parts of the woman's bodies. This represents women's rights, and reveals and compares the freedom given to women by religion, law, and social culture. Islam gives both women and men their rights within certain limits. However, many countries' rules and social culture have limited women's freedom.

It is irrefutable that issues such as gender equality, government policies, and injustice, are a part of any community. Art is one of the gauges of the direction in which progress is moving. Though not all art is quickly accepted by mainstream society, it is nevertheless an expression of the human condition. When these social issues are expressed in any form of art, there is more than enough power to effect social change even in the most smallest of communities (Riedy, 2013).

This illustration of emotions torches feelings which when put into dialogue and motion becomes an active effect of art affecting social change (Lacey, 2014). Artists are those few people who have a need to express themselves. They are neither fearful nor deterred by the political climate even if it means that certain powerful elements would be constantly pursuing them (Ayad \& Blackburn, 2014). An artist's need to express him/herself becomes ever more crucial once he feels that his artistic freedom is in jeopardy. In the reverse side of things, Al-Resayes (2010) argues, art can be influenced by social change as well. The change in times, the signs of progress or the introduction of new methods in government can bring about songs of hope and beautiful art. Through their expressive talents, artists can challenge cultural narratives, shift imagery and inspire emotions in a way that traditional political methods alone rarely do. Artists are principal, not marginal, to social change. As Hamza Serafi ${ }^{5}$ once said, "we

${ }^{4} \mathrm{~A}$ full-length, black outer garment worn by Saudi women in public.

${ }^{5}$ Saudi artist and co-founder of Jeddah's Athr Gallery, a pioneering space that opened in the coastal city of Jeddah in 2009. 
don't deny these issues are part of our community, our society. But what we ask is to see the wider picture. There is a real movement that is happening" (Bencomo \& Wilcke, 2008).

Conceptual works of art, because of the subtlety of their messages, are more likely to get a green light from censors in Saudi Arabia (Al-Resayes, 1999). It is a tongue-in-cheek mixing of popular culture and tradition, and can be debated and understood in countless different ways, helping it escape cases of overt censorship while allowing it to play with political themes.

Certainly, the works mentioned earlier are only a small sample of Saudi artists and artwork, employing contemporary arts as a means of communicating about contemporary controversial subjects. There is no shortage of creative approaches to sensitive topics. While Saudi Arabia may not be the easiest place to produce contemporary art, a growing number of artists are developing new ways to approach the paradox of contemporary art in Saudi Arabia and exploring just where the boundaries lie with a government that is increasingly allowing these boundaries to be redrawn. Art throughout history has often been used as a means to shock an audience; some of the most pioneering images have found disrepute in the media as they represent various controversial themes-which are not always openly discussed. Art allows us to give form and meaning to emotions and to focus on certain issues of a social or political bearing. A controversial image to some is a piece of artwork, which is emotionally invigorating and negates traditional methods of interpretation; it allows the audience's views to be challenged through the notions of shock or surprise. Often it is difficult to determine what relevance controversial art has to society due to the compelling nature of the work.

\section{Discussion}

This part of the study reviews the literature on challenges facing women leaders in Saudi Arabia. There are similarities that women face all around the world but the unique culture in the Saudi Arabia poses a different set of challenges. In western countries, cross-cultural studies on women as managers have found a common rising trend in women's enrolment in leadership positions and found that women managers worldwide share a number of similarities including stereotyping, lack of role models and lack of access to training (Stead \& Elliott, 2009). Research on women in top management positions in Saudi Arabia found that the challenges faced by those women included discrimination at work, cultural taboos, negative attitudes towards working women and lack of confidence and trust in women managers (Wilkinson, 1996).

Surveys conducted identify several inhibiting factors for Saudi women that include organizational factors, such as personnel systems/traditional career paths, male employee attitudes and women's own attitudes. The cultures and customs of the tribal community prevailing in the Arabian Peninsula prior to Islam have contributed to the conservative orientation towards women in Islam (Alajmi, 
2017). Effendi (2003) further argues that because most Arab cultures are patriarchal, a substantial segment of the various Arab societies have, in fact, placed women in a passive role at work and in the family. Therefore, Effendi (2003) maintains that it is not Islam as such that places women in these roles, but rather the way that patriarchal societies interpret Islam to support their positions regarding what is and what is not an acceptable behaviour for women.

A secondary outcome of this research is to highlight the success stories of women leaders in Saudi Arabia despite the immense amount of obstacles they have encountered. Results provide a profile of women leaders in Saudi Arabia as highly educated in various disciplines, with long career experiences and varying degrees of managerial expertise. It is indicative of a policy shift in Saudi Arabia towards enhancing the role of Saudi women in the development process. This study contributed new insights into the dynamics of women's role and development in Saudi Arabia. One objective of this study was to capture the experiences of women leaders in Saudi Arabia and to highlight the challenges encountered by them in order to pave the way for future generations of aspiring women. The results of this study point out that despite their high qualification, job experience and full readiness to assume leadership roles in their organizations, women leaders in Saudi Arabia face several challenges that limit their effectiveness as leaders and prevent them from achieving their potential. The study comes at a time where Saudi Arabia is undergoing a major reform on all fronts but especially in women's issues. Results identify the recent positive changes in women's roles and in the official support to women's participation in public life, which came along as a result of the consistent efforts of the Custodian of the Two Holy Mosques and his conviction of the need to enhance women leadership and participation in the decision-making process at all levels. However, despite these efforts, the Saudi society is nonetheless a deeply conservative one and exhibiting certain content may not be viewed as acceptable.

\section{Conclusion}

It can be said that the role of women in debates regarding societal problems, including the rights of women and especially society's current views on the topic, has inspired a number of Saudi female artists. Their artistic work reveals a previously unknown female history in the home, the woman's social domain, using a method that could gently yet actively change the status quo of power under the umbrella of general social change in the Kingdom of Saudi Arabia. In summary, it is clear that controversial images within modern contemporary art have a significant impact on society. Artists express their thoughts and ideas through their art and by sustaining this freedom of expression they can connect their ideas to an audience, regardless of the subject matter. The above mentioned artists have inspired many Saudis in various ways. Everyone can learn something from a controversial image within modern contemporary art; there is a lot to discover and to take in. All in all, the role of art goes beyond trying to raise awareness. 


\section{Acknowledgements}

The Author would like to thank the Deanship of Scientific Research at Princess Nourah bint Abdulrahman University for funding this research.

\section{Conflicts of Interest}

The author declares no conflicts of interest regarding the publication of this paper.

\section{References}

Abu-Shekhah, N. (1990). Arabic Women and Working in Public Administration in Arabic Countries. Arabic Journal of Administration. Amman, Jordan.

Al-Ahmadi, H. (2011). Challenges Facing Women Leaders in Saudi Arabia. Human Resource Development International, 14, 149-166. https://doi.org/10.1080/13678868.2011.558311

Alajmi, N. (2017). How to Design an Exhibition of a Controversial Context in Environments Where There Are Socio/Religious Constraints-Saudi Women, a Case. $\mathrm{PhD}$ Thesis, Leicester: De Montfort University.

Alassem (1993). Education in the Kingdom of Saudi Arabia (Vol. 1). Riyadh: Dar Tiba.

Al-Atawneh, M. (2009). Is Saudi Arabia a Theocracy? Religion and Governance in Contemporary Saudi Arabia. Middle Eastern Studies, 45, 721-737. https://doi.org/10.1080/00263200802586105

Al-bakar, F. (1997). Saudi Woman and Education: Historical Analysis for Woman's Education in the Kingdom of Saudi Arabia, Egypt. Cairo: Alaialamiah.

Aldehailan, S. (2007). The Participation of Women in Saudi Arabia's Economy: Obstacles and Prospects. PhD Thesis, Durham: Durham University.

AlMunajjed, M. (2010). Women's Employment in Saudi Arabia a Major Challenge. Ideation Center Insight, New York: Booz \& Company Inc.

Al-Resayes, M. (1998). Addendum to the Visual Art Movement in the Kingdom: Visions of Visual Art. In Special Publication of the 14th Janadria Women's Visual Arts Council. Riyadh: National Festival of Tradition and Culture.

Al-Resayes, M. (1999). Visual Arts in the Kingdom of Saudi Arabia. Selections from Saudi Visual Arts: Traveling Exposition, Taywan Taibia. Riyadh: Saudi Arabian Organization of Culture and the Arts.

Al-Resayes, M. (2010). The History of the Visual Arts in the Kingdom of Saudi Arabia. Riyadh: Ministry of Culture and Information.

Al-Senan, M. A. (2007). The Saudi Woman and Visual Arts. Riyadh.

Al-Shetaiwi, A. (2002). Factors Affecting the Underutilisation of Qualified Saudi Women in the Saudi Private Sector. $\mathrm{PhD}$ Thesis, Loughborough: Loughborough University.

Athimin, A. S. (1995). The History of the Kingdom of Saudi Arabia (Parts 1 and 6). Riyadh: Obaikan.

Atkinson, M. (2015). Art Is Halal' Poster Campaign Sparks Lively Debate in Saudi Arabia. London: Middle East Eye.

Ayad, M., \& Blackburn, V. (2014). Contemporary Kingdom, the Saudi Art Scene Now. Dubai: Canvas Central.

Baki, R. (2004). Gender-Segregated Education in Saudi Arabia: Its Impact on Social 
Norms and the Saudi Labor Market. Education Policy Analysis Archive, 12, 1-12. https://doi.org/10.14507/epaa.v12n28.2004

Bencomo, C., \& Wilcke, C. (2008). Separating Image from Substance in Saudi Arabia. Middle East Report, 48, 2-4.

Ben-Mahfodh, A. (1997). Rights and Issues of Woman in Modern Society.

Devos, A. (2004). Women, Research and the Politics of Professional Development. Studies in Higher Education, 29, 591-604. https://doi.org/10.1080/0307507042000261562

Effendi, A. (2003). Enable Workers: An Introduction to the Improvement and Continuous Development, the Arab Organization for Administrative Development. Riyadh: IPA.

Elamin, A. M., \& Omair, K. (2010). Males' Attitudes towards Working Females in Saudi Arabia. Personnel Review, 39, 746-766. https://doi.org/10.1108/00483481011075594

Hamdan, A. (2005). Women and Education in Saudi Arabia: Challenges and Achievements. International Education Journal, 6, 42-64.

Hazlitt, W. (1830). On the Spirit of Controversy.

Ibrahim, A. A. (1998). Records of the Saudi Arabian Organization of Culture and the Arts. Riyadh: President's General Office of Protecting Youth.

Lacey, R. (2014). Inside the Kingdom. New York: Penguin Books.

Lacroix, S., Haykel, B., \& Hegghammer, T. (2015). Saudi Arabia in Transition. New York: Cambridge University Press. https://doi.org/10.1017/CBO9781139047586

Obaid, S. (2011). Women of the Holy Kingdom.

Riedy, R. T. (2013). Multilingual Creative Reformists: Saudi Arabian Women's Ingenuity in Overcoming Economic, Religious and Cultural Barriers to Career Success. PhD Thesis, Seattle: University of Washington.

Saddeka, A. (1994). Women and Words in Saudi Arabia: Politics of Literary Discourse. New York: Columbia University Press.

Stead, V., \& Elliott, C. J. (2009). Women's Leadership. Basingstoke: Palgrave Macmillan. https://doi.org/10.1057/9780230246737

Wilkinson, G. (1996). Women in Business. Dubai: Gulf Business. Womensmemorial.org. 